\title{
MOVIMENTO E ANIMAÇÃO DAS FESTAS, VISITAS, ANDANÇAS E CHEGADAS ${ }^{1}$
}

Graziele Dainese

Um homem vai devagar. Um cachorro vai devagar. Um burro vai devagar. Devagar... as janelas olham. Eta vida besta, meu Deus. Neste poema, Drummond (2002 [1930]) cria um ritmo de vida que, embora relacionado à cidadezinha qualquer, também poderia servir de epígrafe para algumas descrições sobre a vida na roça. É este ritmo que faz Oliveira Viana (1955 [1949]) lamentar, quando apresenta as comunidades do meio rural brasileiro como arranjos sociais isolados, marcados pela falta de contato entre as pessoas. Na obra de Oliveira Viana, a existência no campo, associada a um mundo de distâncias (que é, ao mesmo tempo, um mundo de ausências), não deixa de ser vista sob o tom da banalidade. Por comparação, bem mais vivaz é a imagem da vida camponesa europeia criada pelo autor: relações qualificadas se tecem nas aldeias, dado que a proximidade geográfica, tal como vivida nesses lugares, supõe uma existência gregária e variante. ${ }^{2}$

A possibilidade de uma vida em comum, assim como de uma existência variada está localizada nos centros urbanos, principalmente quando são comparadas à roça. Neste sentido, a cidade motiva em quem mora no campo a disposição de romper com um tempo de demoras e de imobilidade, visto que o deslocamento do homem do campo quando ocorre é para alcançar a cidade. Em diversos estudos que tratam da mobilidade camponesa, não é estranha a ideia de que a roça se movimenta para alcançar seu fim. Quando se trata de relativizar os efeitos dessa mobilidade, pode-se falar sobre a roça que permanece após a ida das pessoas para a cidade. Deste ponto de vista, o que aparece é a experiência de um lugar que se atualiza nas mulheres, nas crianças, nos velhos que ali persistem, num roçado que se cultiva com o dinheiro vindo do trabalho na cidade, na esperança do retorno que é cultivada por aqueles que partem. ${ }^{3}$

A despeito dessas caracterizações, os moradores de Santa Abadia do Pradinho, município localizado na região Alto Paranaíba (Minas Gerais), reconhecem que a vida nas localidades rurais pode ser mais interessante do que a vida na cidade. ${ }^{4}$ Formado pelo diminuto núcleo urbano (a cidade) 
e por mais de 20 localidades rurais, o interessante para esse município é o "movimento", criado principalmente (mas não exclusivamente) pela circulação de pessoas. O vai e vem pode ser intenso em alguns momentos do ano e é essa intensidade que faz a diferença entre a roça e a cidade. Dizem os abadinhenses: 'a roça é mais movimentada do que a cidade ${ }_{1}^{5}$ contrariando assim tantas outras qualificações que a desfavorece quando comparada à existência urbana. ${ }^{6}$

É o que acontece na roça que incentiva o deslocamento dos moradores da cidade, principalmente durante os finais de semana, período em que as festas religiosas, mas também as casas dos parentes e conhecidos tornam-se tão atraentes. Por sua vez, os festejos refletem e intensificam as trocas cotidianas, baseadas na circulação de pessoas e objetos. Essa circulação, que tem como referência a vida na localidade, é significativa para os moradores da Terceira Margem, a ponto de defini-los. Reconhecendo menos a extensão dos seus próprios deslocamentos, mas sobretudo os parâmetros que os definem (parâmetros que têm como perspectiva a "comunidade"), os margeenses se veem como 'gente de pouco movimento, se vai volta'. Os deslocamentos mais permanentes para outros estados e municípios, frequentes em especial para a busca de emprego e de melhores condições de vida, são descritos a partir do pressuposto de que 'quem vai, volta' ou, ao menos, deveria voltar. Relatos de pessoas que se mudaram para Goiás ou para outras cidades e regiões do estado de Minas Gerais ganham o tom dos retornos. E mesmo aqueles que não voltam como moradores, não deixam de chegar, e o fazem como "visitas".

É essa valorização do movimento que conduz a escrita deste artigo, que busca traduzir a proliferação e a especificidade das motivações, dos sentidos e dos circuitos que se encontram subsumidos nos trânsitos ali vividos. Este foco tem como um dos seus objetivos escapar aos recortes mais ou menos fixos dados às direções e aos sentidos da mobilidade, a exemplo das abordagens que visam traduzir toda e qualquer movimentação segundo o pressuposto da partida-chegada. Tal como problematizam Moacir Palmeira e Alfredo Wagner Berno de Almeida (1977) ao proporem uma genealogia da categoria migração, a qualificação dos movimentos a partir desse pressuposto tem como consequência limitar o conhecimento da variação dos deslocamentos, tanto dos seus significados quanto dos seus sentidos.

Atenta a estas questões, minha abordagem dos movimentos vividos na Terceira Margem destaca a importância das relações entre próximos (atualizadas pela família e pelo parentesco). A ênfase sobre essas relações se justifica na medida em que os movimentos não deixam de expressar um ideal encontrado na vivência entre "parentes" e "conhecidos". Assim como 
essas relações incentivam os deslocamentos, elas também são influenciadas por acontecimentos criados nessas movimentações. Veremos adiante que a correlação entre esse ideal de vida (baseado na proximidade) e os "movimentos" que deslocam as pessoas não é exclusividade dessa localidade rural, pois se atualiza em realidades bastante diversas. Etnografias como a de Comerford (2013), Carneiro (2014), Andriolli (2011), Dumans Guedes (2014), Pissolato (2007), Allerton (2012), Ellis (1996) e Teixeira (2014) refletem a maneira como o parentesco produz movimentações (ou predisposição para tal) do mesmo modo que as vivências da família e dos parentes são marcadas pela tendência movente característica desses modos de vida.

O foco na relação entre próximos (vistas aqui a partir da convivência entre "conhecidos" e "parentes"), além de permitir relativizar a centralidade dada aos processos econômicos no incentivo aos deslocamentos (tal como supõe certo recorte sobre as migrações), permite abordar outras dimensões dessa mobilidade e resgatar aspectos do gosto pelo movimento, cuja referência constante, antes de afirmar um acontecimento extraordinário na vida de quem se desloca, diz respeito a uma modalidade de engajamento com o mundo (Ingold 2011).

Na Terceira Margem, a geografia da localidade, marcada pela proximidade das casas, parece afirmar em si mesma essa valoração dos movimentos que se fazem na direção dos lugares onde estão os mais chegados. No entanto, se essa espacialidade sugere a aproximação, ela não é a única condição para a efetuação das relações entre os mais íntimos, tampouco é um ponto fixo ou anterior às próprias relações e aos movimentos ali vividos. Tanto a geografia quanto a proximidade são acontecimentos do exercício constante da mobilidade, pois sua existência não independe dos trânsitos das pessoas.

O "movimento", que é significativo do modo de vida dos moradores dessa localidade rural, encontra nas práticas de circulação orientadas pelo "receber bem", "visitas", "ajudas" e outras "chegadas" um meio importante para se efetuar. Os deslocamentos e as concentrações, por sua vez, incentivam a circulação de objetos, palavras e forças que podem transformar o ritmo da vida: é quando o "movimento" se faz "animação". Como será descrito, esse estado de coisas é mais do que mobilidade e/ou circulação. A "animação" traduz o "movimento" enquanto aceleração, sugerindo outro ritmo de vida: uma frequência que pode alterar o comportamento e as ações.

É também a partir dessa busca e desse gosto por andanças, chegadas e animações que pretendo discutir a correlação entre a experiência do movimento e os aspectos significativos da vida na Terceira Margem. No final dessa descrição sobre os diversos modos de mover e de fazer mover, indico a associação existente entre um modo de conhecimento e as andanças, que se faz presente na expressão nativa "andar é conhecer". 


\section{Receber bem - os movimentos da hospitalidade}

O trânsito frequente de pessoas para a Terceira Margem qualifica o modo de vida local tanto aos olhos dos seus moradores quanto aos olhos de quem a conhece mas não mora ali: o lugar é 'movimentado'. O vai e vem que conduz ao lugar é um dos elementos que reforçam essa imagem. Nos finais de semana, quando é tempo de festejar os santos padroeiros, os deslocamentos se intensificam e a localidade se torna alvo de muitas chegadas: as casas recebem parentes e conhecidos, a capela local fica 'cheia de gente'.

Mas o "movimento" (que tanto agrada os moradores e que dá fama às suas festas) não deriva apenas desses deslocamentos. Horas antes da chegada dessas pessoas, o que se observa é um trânsito constante dos moradores, que irrompem de suas casas para encontrar a capela e de lá se irradiam para as casas dos vizinhos, a fim de solicitar seu auxílio, de buscar um objeto ou de apenas parar para uma conversa rápida. Afinal, nesses momentos, se alguém não participa ativamente do vai e vem, ao menos sai de casa para acompanhá-lo com os olhos. A festa demanda e cria um fluxo que é próprio dos moradores da localidade e, por sua vez, chama a gente que chega. ${ }^{7}$ Sendo assim, o "movimento" se faz com os deslocamentos que buscam a comunidade e com os trânsitos ali vividos, os quais entram em consonância a partir da tendência hospitaleira característica do modo de vida local.

Próxima ao núcleo urbano de Santa Abadia do Pradinho, a Terceira Margem é uma localidade de fácil acesso às pessoas que querem frequentá-la. A condição das estradas permite a chegada rápida, que pode ser feita por carro, moto ou a cavalo. A frequência diária de ônibus, que conduzem as crianças e os adolescentes às escolas do município, também é uma oportunidade de chegar ao lugar. No entanto, se a vizinhança do urbano é uma condição importante que permite o deslocamento até o local, esta não é a única condição. Tão fundamental quanto os veículos e as estradas é a maneira como os moradores valorizam as chegadas.

O "movimento" está associado à dinâmica da hospitalidade (o "receber bem"), pois do mesmo modo que incentiva, ele é incentivado por essa prática. Traduzindo exemplarmente tal associação, os festejos religiosos são momentos privilegiados para esse exercício hospitaleiro, afinal, sua ocorrência traz pessoas às localidades e estas se sentem atraídas pela maneira solícita com que serão recepcionadas nas capelas e nos salões. A recepção dos moradores atrai as pessoas ao local à medida que se reconhece no povo da roça um gosto por 'receber visitas'.

Eu mesma encontrei nesse gosto as condições para a realização da pesquisa de campo. No início, a existência de tantas casas dispostas no nú- 
cleo da comunidade suscitou em mim a ideia de alugar uma delas. Ouvindo meus projetos, as pessoas com quem convivia na cidade estranharam esses planos e logo me dissuadiram do intento: 'na roça, não há casas para alugar, elas estão todas ocupadas pelas famílias', disse-me o presidente do STR. A inexistência de lugares disponíveis tampouco encerrava uma impossibilidade de contato mais permanente com os moradores, e esta mesma pessoa assinalou as condições para minha aproximação: 'mas você pode visitá-los, o povo gosta de receber'. A informação se baseava na sua própria relação com a Terceira Margem, marcada por trânsitos constantes ao local vividos principalmente em momentos bastante adequados para fazê-los: as festas dos santos padroeiros. ${ }^{8}$

Essa tendência hospitaleira permite a chegada à comunidade e o contato com seus moradores, algo que se torna notável aos olhos de quem não é de lá, principalmente nos tempos de festa. Do mesmo modo, os margeenses entendem que essa recepção é uma condição importante para a festa. Como me disse um dos organizadores do festejo daquele ano de 2009, "receber bem" chama gente e faz tudo ficar mais "animado". Apesar de também conhecer momentos mais intensos (no comércio do dia a dia e, em especial, no contexto que o inflama, a "política"), a "animação" que falta ao núcleo urbano nos finais de semana mais ordinários faz com que as pessoas busquem essas festas, chegando antes ou depois da missa rezada nas capelas que povoam o meio rural abadinhense.

Entre os moradores da Terceira Margem, o "receber bem" pressupõe a disposição ao contato, a qual é caracterizada pelo matiz da intimidade. Um dos lugares privilegiados para essa forma de aproximação são suas casas. É em casa que o anfitrião se apraz em dedicar atenção a quem chega, e ela se expressa de diversas formas, a depender de quem se aproxima, o que pode exigir a pausa no trabalho, a oferta de alimento e a dedicação à conversa. Mesmo em lugares menos privados, tal como as capelas e os salões, o exercício do "receber bem" dá o tom doméstico ao convívio. Estar atento ao bem-estar dos convivas, servindo-lhes alimento e bebida nas mesas, observar se estão bem acomodados e permanecer junto daqueles que chegam às festas da localidade são formas de receber que se assemelham àquelas que o anfitrião dedica a quem chega à sua casa.

As pessoas que buscam as festas são recebidas como se recebe uma "visita" e é enquanto tal que ela transita no dia a dia. É o "receber bem" que define quem chega e como se chega, afirmando, em função de seus procedimentos quem é e quem não é "visita". Embora durante os festejos a comunidade abra as portas às pessoas, nem todas são alvo da atenção dos moradores. O convite prévio à chegada e a dedicação à presença são fatores 
que definem quem é "conhecido" e quem é "de fora". Aqui se destaca um aspecto importante, pois é aos "conhecidos" que se dedica hospitalidade: o contato qualificado demanda que o estranho não seja tão estranho assim. A recepção permite ao "conhecido" ser "visita" e é esta condição que lhe possibilita circular pelo lugar, adentrando o salão ou optando por permanecer nas suas imediações. À medida que frequenta com mais assiduidade os festejos, o "conhecido" pode chegar sem convite, assim como pode ir à comunidade e ser recebido em situações mais cotidianas. As portas fechadas das salas das casas não são um sinal de interdição, mas sim a afirmação de que para ele há uma entrada mais privilegiada, dada pelo acesso direto à cozinha.

Em se tratando da "gente de fora" se, por um lado, a falta de convite não impede a presença, por outro, lhe restringe a permanência. Seus deslocamentos pela área externa da capela e a estranheza com que se percebe a circulação dessas pessoas no dia a dia são sinais que explicitam a ausência da dedicação hospitaleira e constrangem a mobilidade de quem ali não é bem recebido.

Do "receber bem" derivam práticas, como o "fazer visita" (ou "visitar"), as quais qualificam os trânsitos de quem chega à comunidade, pois quem foi recebido como "visita" provavelmente poderá voltar ao local. Assim como o "movimento" é exercitado pela hospitalidade, tal exercício, por sua vez, cria a condição de "visita", que favorece os deslocamentos em momentos menos extraordinários do que as festas.

A "visita" também conecta aqueles relacionados pela proximidade geográfica e por outras experiências destacadas como propiciadoras de relações. Neste caso, se os procedimentos da recepção e das chegadas não são os mesmos que aqueles que regem a relação com os mais estranhos, isto não significa ausência de parâmetros. A aparente informalidade na recepção de um vizinho que vai a uma casa traduz em si mesma uma forma de receber: àqueles mais chegados (que assim são definidos justamente por serem presenças mais constantes) pode se dispensar a parada no trabalho e a oferta do café e dos biscoitos (para citar alguns dos marcos significativos do "receber bem"). De sorte que essa recepção não se reproduz da mesma forma entre todos os moradores, pois se a proximidade geográfica faz de todos vizinhos, é a circulação pelas casas que transforma uns e outros em "conhecidos". Veremos que nesses contextos relacionais a constância dos movimentos dá o tom das variações tanto dos pertencimentos quanto das formas de se movimentar: transforma o ato de "visitar" ao lhe conferir os contornos das "ajudas", matiza as "ajudas" em linhas mais tênues, formando diversas possibilidades de chegada. 


\section{Transformando chegantes em chegados}

Mais do que vizinhos é a condição de "conhecidos", assim como a de "parente", que define a formação do coletivo comunitário. 'Aqui são todos conhecidos, aqui são todos parentes' é a expressão ouvida quando se caracteriza a Terceira Margem e seu efeito não se limita à retórica, à medida que há um investimento dos moradores em fazer com que a proximidade não se limite à geografia. Tão importante quanto morar na localidade é frequentar as casas uns dos outros. De certa perspectiva é esse trânsito que garante a própria existência da Terceira Margem como "comunidade".

Em trabalho anterior, ao descrever os diversos sentidos do termo "Comunidade" entre os margeenses (Dainese 2011), chamo a atenção para a correlação existente entre ser uma "comunidade" e ter "movimento". Embora a existência da capela seja uma condição importante para alguns lugares terem mais "movimento" (dado que ela possibilita a participação no calendário de festas), isto não garante a concentração desejada nos festejos. Para tanto é preciso que uma comunidade seja "comunidade unida". O adjetivo que qualifica a comunidade ("unida") é derivado de uma convivência que se partilha cotidianamente e que não prescinde da circulação e dos trânsitos dos moradores pelas casas uns dos outros. Pode-se dizer que lugares que têm "movimento" são "comunidades" no sentido pleno do termo. Sendo assim, ainda que nos registros municipais esta seja a designação usada para marcar territórios rurais, do ponto de vista de quem vive nesses lugares, a tradução do termo diz respeito mais a um modo de vida marcadamente movente do que de fato a um espaço. Voltarei a falar sobre isso.

A frequência dos trânsitos vividos nas casas faz com que alguns moradores sejam mais "conhecidos" do que outros. A chegada mais rara incita um tratamento semelhante àquele dado a quem não mora ali: a parada no trabalho e a oferta do alimento reforçam os parâmetros da hospitalidade, criam a "cerimônia", e fazem com que alguns vizinhos sejam mais "visitas". Nesse contexto, ainda que as chegadas às casas sigam o hábito de "visitar", à medida que se fazem mais visitas, isto deixa de ser "visita". Essa transformação assinala a intimidade criada dentro de casa, a qual reforça os laços entre os moradores.

Assim como a afluência constante pode transformar a condição da visita, ela também traduz outras práticas de circulação. Dessas, destaca-se a "ajuda", que sinaliza vínculos ainda mais estreitos, afirmados nas noções de "parente" e de "família". Quem chega a uma casa e acompanha o ritmo do trabalho ou quem é chamado a sair de sua própria casa para seguir o vizinho em suas tarefas é aquele cuja intimidade usufrui das prerrogativas da consanguinidade e/ou da afinidade. 
Do mesmo modo que a "visita", a "ajuda", quando constante, é modulada por chegadas menos marcadas pelo imperativo que a define (nesse caso, o auxílio), visto que ambas são incentivadas por outras trocas (também comuns entre aqueles que são mais chegados), a exemplo do intercâmbio de alimentos, como um pedaço do bolo feito naquele dia ou da carne fresca do porco, que anteriormente também foi recebida por quem agora oferece. A peculiaridade sociológica da "ajuda" a ser assinalada aqui diz respeito aos trânsitos suscitados pela disposição ao auxílio-mútuo e sua associação à família e ao parentesco. Mas tal associação não se baseia apenas no fato de que ajuda é uma prática vivida por quem é da família ou por quem é parente, mas, sobretudo, porque essa prática influencia a formação desses coletivos. Afinal, esperar ajuda de um "parente" é algo que se observa, já que este é um pressuposto "da família" ('é a obrigação'). No entanto, isto não significa que tal pressuposto não seja questionado, não apenas porque às vezes o auxílio não vem de onde há expectativas, mas também porque acontece de ele vir de onde menos se espera.

Embora a afinidade e a consaguinidade sejam fatores importantes na configuração da família e do parentesco, os vínculos também se reforçam ou se enfraquecem enquanto se vivencia a intimidade criada nos trânsitos pelas casas. Do mesmo modo, a conexão entre as pessoas que não são parentes pode se estreitar quando tecida nos circuitos domésticos. Esses argumentos derivam da observação de relações como a de Joanin e o menino Ari. Quando questionei a avó de Ari - a Quirina - se Joanin era "parente" de Ari, a senhora me respondeu: 'é como se fosse'. E me explicou que Joanin cuida de Ari desde quando sua mãe deixava seus filhos ao léu sem maiores cuidados. Compadecido com a situação do menino, Joanin passou a lhe dedicar atenção, dando alimento, observando horários do banho, do sono, das aulas. Mesmo com avós e tios residindo na Terceira Margem, toda vez que chega da escola é para a casa de Joanin que Ari se encaminha. Joanin procurando Ari pelas localidades é fato comum para todos, tanto que em casa dos "parentes" de Ari, a exemplo de sua avó e de suas tias, Joanin pode ir entrando, sem 'fazer cerimônia'. Mal chega e já está na cozinha perguntando à avó do menino se ele não vai para casa tomar banho. Ainda que Joanin não seja chamado por algum termo de parentesco que possa enunciar, desse modo, a proximidade existente entre ele e os "parentes" de Ari, é notável que seja recebido nessas casas como se fosse parente. O reconhecimento da sua disposição (a 'obrigação' que lhe devem) se dá na maneira como é recebido em casa da avó de Ari: a chegada se faz em silêncio, apenas para assuntar, e às vezes sai e nem se despede. Tendo em vista que nem os consanguíneos e afins seguem o mesmo ritmo quando se 
trata de cumprir ou de receber a 'obrigação', as características que marcam as relações de Joanin com Ari e sua família não deixam de determinar a força desse parentesco.

Também se define como "ajuda" a participação de pessoas na organização das festas da comunidade. Nesses contextos, é esperado dos moradores da Terceira Margem o auxílio na preparação da comida que será vendida no salão, na decoração da capela e na recepção de quem chega. No entanto, há aqueles que participam dessa forma, mas não moram ali: vêm do núcleo urbano ou das localidades rurais vizinhas. E há também aqueles que de tanto ajudar já não se sabe de onde é que eles vêm. Este é o caso de inúmeros moradores das adjacências da Terceira Margem, de Arraial da Samarra e de Cumbucas (para citar apenas duas das localidades vizinhas), que transitam por esses lugares em períodos de festas, mas frequentemente o fazem em outras épocas. Desse modo, mantêm relações com seus parentes e conhecidos.

No entanto, nem todos que participam estão ligados pelo sangue ou pelos laços de casamento, mas é através dessa circulação entre comunidades que estreitam vínculos e, por meio dos pertencimentos assim cultivados, embaralham os territórios. 'João Batista mora em Cumbucas? Mora sim, mas é da Samarra, é também da Terceira Margem, pois não há festa que não se conte com João Batista', foi o comentário de um morador da Terceira Margem ao falar do vizinho geograficamente distante, mas existencialmente próximo. O fato é que os moradores de outras localidades rurais, ainda que não sejam vizinhos, também podem ser próximos, tornando-se parte da comunidade.

Ao fomentar a circulação, o calendário das festas dessas localidades rurais transforma seus limites pelo vai e vem dos seus moradores. Se o interesse é definir onde termina e onde começa a comunidade nesses contextos, a experiência dos Parceiros do Rio Bonito, tal como descrita por Antonio Candido (1977), é uma referência importante. Pois, assim como foi observado nos bairros rurais paulistas, nessas localidades de Minas Gerais, o pertencimento segue o ritmo festivo, de sorte que as festas têm papel significativo na agregação.

A circunscrição é sempre parcial, pois está constantemente em definição. Vimos que, através do exercício da hospitalidade, a Terceira Margem abre suas portas principalmente aos "conhecidos". Nesse sentido, a disposição anfitriã incentiva a circulação e, ao mesmo tempo, define suas formas ao afirmar, em seus próprios procedimentos, quem é "conhecido" e quem é "de fora". Nestas definições estão implícitas as possibilidades de chegar, transitar e se relacionar com os moradores. No entanto, do mesmo modo com que as formas de receber criam os parâmetros para o contato entre as pessoas, elas podem transformar o próprio contato, fazendo com que os chegantes se tornem mais chegados. 
Não faltam exemplos de pessoas estranhas que passaram a partilhar do convívio local, a ponto de se tornarem dignas da recepção e do reconhecimento dos moradores: mendigos, comerciantes e a pesquisadora são exemplos de presenças que, dada a sua a constância, puderam de uma forma ou de outra usufruir da recepção que transforma o estranho a partir da intimidade que se estabelece. Os políticos também são exemplos de como o traço estrangeiro pode ser modulado à medida que a circulação pela comunidade segue os parâmetros do "visitar". Ainda que tais presenças encontrem no "tempo da política" (definição para o período associado às campanhas eleitorais municipais) o convite para estar nas localidades, é fato que o político que sabe aparecer em tempos não eleitorais pode encontrar condições de circular mais livremente, de forma mais próxima dos moradores. Chegando nas festas, principalmente naquelas em que a intenção pela busca de votos não é tão explícita (o que se torna possível quando a festa não coincide com a campanha), o político pode se tornar "conhecido". Tal condição, apesar de nem sempre lhe garantir votos, ao menos lhe permite circular de forma menos estrangeira pelo local. A condição de "conhecido", criada em função de chegadas constantes, favorece-o quando se apresenta como candidato: ela se torna moeda importante num momento em que a indiferença, além de desvantagem eleitoral, é atualizada na comunidade sob os parâmetros da circulação ('Quem é este? Nunca o vi andar por aqui').

\section{No passo das chegadas: limites e variações}

Desde o calendário das festas e da dinâmica de participação que as capelas locais promovem, vimos que as movimentações das pessoas embaralham pertencimentos e as próprias localidades. Do mesmo modo, as visitas de antigos moradores, motivadas pelas saudades dos parentes ou pelo "pagar visita" que um margeense fez a eles em algum momento, indicam uma circulação mais ampla e criam uma convivência que, apesar de existir na distância geográfica, encontra referência nessa "comunidade" da qual se desfruta em chegadas constantes e/ou esporádicas.

Essas situações afirmam a seu modo uma tendência descrita nos estudos que retratam como o deslocamento de pessoas por contextos diversos pode estender a vivência local em outras escalas. Análises como a de Thomas e Znaniecki (1974 [1918]), ainda que preocupadas com questões como migração e assimilação dos poloneses nos Estados Unidos, nos falam também de uma América vivida sob as influências do lugar de onde se partiu, influência esta cultivada pelas cartas dos camponeses que seguiam da Polônia para 
o país americano (e vice-versa). As notícias das festas de casamento, dos negócios sobre a propriedade da terra lá deixada e as fofocas estreitavam o mundo dos migrantes, fazendo com que esse lugar se tornasse mais próximo.

Em outros casos etnográficos, as extensões dos lugares, criadas por múltiplos trânsitos, se fazem a partir da sobreposição de práticas diversas de movimento, tal como se apresentam nos deslocamentos entre cidades vividos pelos moradores do Vale do Jequitinhonha e do Cerrado Mineiro (Comerford 2013; Carneiro 2010), ou na mudança de chão de morada sempre presente na experiência dos moradores do sertão de Inhamuns, no Ceará (Teixeira 2014). Esses estudos indicam como a sobreposição existente de visitas, chegadas, mudanças modulam a distância e proliferam os movimentos, formando uma trama de circulações que se compõe com outras mobilidades.

Essas são situações que permitem questionar até que ponto experiências como migração, deslocamento campo-cidade, êxodo rural não replicam uma tendência movente que é constitutiva desses modos de vida. De sorte que descrever a chamada mobilidade camponesa partindo unicamente de imperativos econômicos ou da ideia de que os deslocamentos são acontecimentos extraordinários nessas experiências é não atentar para a variedade de motivações e, principalmente, dos movimentos que afetam esses modos de vida. Antes de ser um fenômeno criado por influências exteriores às experiências, tal variação indica que a vida para essas pessoas se faz em constantes movimentações.

Se levarmos a sério o que está em questão em tais deslocamentos e circulações, perceberemos que, ao modular as distâncias geográficas, a sobreposição de práticas de circulação complexifica os espaços nos quais se faz a convivência. Afinal, partindo dessas dinâmicas, fica difícil precisar até que ponto a separação entre municípios e/ou entre outras circunscrições territoriais mais formais pode ser medida em quilômetros ou em termos existenciais.

Tais vivências matizam o impacto da distância geográfica no convívio de pessoas que não partilham mais o espaço físico, quando não conduzem ao questionamento da prerrogativa do espaço em determinados modos de vida, a exemplo da constituição dos territórios de parentesco descritos por Comerford (2013) a partir das práticas de vigiar e narrar os movimentos vividos no Vale do Jequitinhonha e na Zona da Mata Mineira. Nesses territórios, as circunscrições das relações e dos sujeitos são criadas na medida das andanças e dos assuntos que elas geram, de modo que vigiar e narrar problematizam os movimentos de si e dos outros, provocando misturas e separações de povos e pessoas e, assim, embaralhando os limites administrativos e jurídicos. ${ }^{9}$ 
Olhando a Terceira Margem a partir dessas experiências e do fato de que para os margeenses a "comunidade", mais do que território, é um modo de conviver (baseado na proximidade, na relação com parentes e conhecidos, na circulação que qualifica a própria proximidade), pode-se dizer que esse modo é reproduzido nas movimentações e, mais do que isso, que estas são constitutivas do próprio convívio, visto que a proximidade não prescinde dos trânsitos e da circulação vivida pelas pessoas. Os movimentos mexem com as distâncias a partir do desejo da proximidade, mas também formam a própria proximidade.

É através do "receber bem" que os moradores criam as possibilidades de modular a estranheza, fazendo com que se tornem "conhecidos". A hospitalidade permite e incentiva a circulação de modo a ampliar a própria comunidade. Ao incentivar a visita, essa abertura cria uma comunidade de parentes e conhecidos, cuja definição não se resume às limitações geográficas da Terceira Margem.

Mas já que não se chega de qualquer maneira a uma casa, o "receber bem" é um modo de gerir as condições da circulação e, por consequência, da aproximação. Vir como "visita" demanda que algum contato deve existir entre o anfitrião e o hóspede, pois, como foi dito, a hospitalidade é exercício próprio dos "conhecidos". O convite ao fazer-se presente indica a existência de tal relação. Sendo assim, o "receber bem", ao assinalar a disposição ao contato, circunscreve as circunstâncias para sua ocorrência. Chegar a casa, aceitar o café e a comida ofertados são atitudes que concorrem para o comportamento do anfitrião, que se baseia em se dedicar àquela presença, principalmente através das conversas que não podem rarear. Da mesma forma, entrar pela porta da sala (indicativo de uma distância das relações, que se reconhece quando se sabe que alguém mais próximo sempre entra pela porta da cozinha) e poder circular por outros ambientes, apenas se convidado pelo dono da casa. Estas e outras ações, aparentemente insignificantes, indicam que a abertura ao contato não prescinde de determinadas demarcações.

Mas ao circunscrever limites, a hospitalidade os problematiza, tensionando sua fixação ou porosidade. Tal problematização pode ser pensada a partir da transformação dos vínculos e dos pertencimentos, cujo acontecimento é apontado por Pitt-Rivers (2012 [1977]) ao propor uma lei geral da hospitalidade. Segundo o autor, os atos de receber modulam as aproximações e os distanciamentos entre hóspede e anfitrião, e ainda que tais atos não suspendam a ambivalência constitutiva dessa relação, eles são suficientes para uma mudança na natureza do contato com o estrangeiro. No caso etnográfico que aqui apresento, as reflexões de Pitt-Rivers (2012 [1977]) 
sobre a lei da hospitalidade são significativas para a discussão, tanto para falar sobre as formas de lidar com o estrangeiro quanto sobre os modos de convivência entre parentes e os conhecidos. Afinal, a dinâmica de circulação nesta comunidade não pressupõe uma distinção estanque entre aqueles que se movem: o "de fora" e o "conhecido", antes de identidades referidas aos lugares de origem, são condições criadas por tantas chegadas, já que o próprio vizinho pode ser marcado por um traço estrangeiro quando comparado a um mais próximo. Nestas circulações, orientadas pela hospitalidade, os limites relacionais são tensionados constantemente e, no caso dos parentes e dos conhecidos, os modos de receber e de se fazer presente nas casas também são acontecimentos significativos para a variação relacional.

A dinâmica da hospitalidade margeense é transformadora de vínculos e a seu modo reafirma tendências descritas de outros contextos de relações entre anfitrião e hóspede (Pitt-Rivers 2012 [1977]; Allerton 2012; Munn 1992) tanto no que compete às variações de pertencimento quanto à sua capacidade de gerir as condições de circulação e de contato (Pitt-Rivers 2002 [1977]; Allerton 2012). Mas a presente experiência também destaca que, estando o "receber bem" associado a uma das principais maneiras de criar o "movimento", é significativo que essa movimentação tenha influência na transformação de vínculos e na da própria dinâmica hospitaleira. Os exemplos de chegantes que se tornam mais chegados, dos parentes que são tidos como mais próximos e/ou mais distantes afirmam a transformação relacional que é criada pelas movimentações, do mesmo modo que demonstram como suas idas e vindas afetam os parâmetros da recepção e das possibilidades de chegar e circular. Embora o "receber bem" se mantenha como tendência significativa na recepção de parentes e conhecidos, entre os mais chegados é possível abrir mão da "cerimônia", cuja ocorrência afirma inequivocamente as condições da hospitalidade. À medida que se chega é possível se movimentar de maneiras diversas, seja na frequência, seja nos modos de circular pelas casas.

Destaquei anteriormente como alguns trabalhos (Comerford 2013; Carneiro 2014; Teixeira 2014) retratam a pressuposição recíproca de práticas de circulação e diversas experiências de deslocamento (migrações e andanças outras). Com o exemplo da Terceira Margem, quero chamar a atenção para a variação das movimentações e como ela influencia a dinâmica da hospitalidade ("receber bem"). Pois ainda que a hospitalidade seja um dos principais meios de efetuação da tendência movente, a maneira como ela é vivida não se limita ao "receber bem".

Embora as movimentações encontrem na "visita" um modelo antropológico significativo para as diversas maneiras de circular, ela não encerra 
todas as possibilidades de efetuar o "movimento". Nem todas as chegadas são visitas, tampouco a relação entre o dono da casa e a pessoa que chega pode ser definida pelos traços que efetivam explicitamente o "receber bem". Afinal, à medida que a circulação modula o contato, o contato também modula a própria circulação, criando variações significativas na forma de concebê-la e de vivê-la. O que se observa é a pressuposição recíproca entre a transformação relacional e os modos diversos de circular e de fazer "movimento". Do mesmo modo, essa pressuposição deve ser pensada como uma das criações da tendência movente característica da vida na Terceira Margem.

Mas se as formas de chegar e de receber variam quando se observa que a chegada e a recepção são vividas entre pessoas próximas, isto não significa que a circulação que põe em contato os conhecidos prescinda de seus próprios modos para se dar. Nesse sentido, as casas se destacam como referência para os trânsitos vividos na Terceira Margem não apenas porque é comum que o ir e vir das pessoas passe, em algum momento, por elas, mas principalmente porque é nelas que o contato se torna mais pleno, que a chegada é valorizada a ponto de ser incentivada e de ser transformada. Nas casas, o "movimento" encontra pausa, e a centralidade desses lugares não denota que ali haja fixação ou permanência, pois essa pausa não corta seu fluxo, apenas o qualifica. Mais do que permanência, podemos designar tais pausas como durações. ${ }^{10}$ Indiquei a importância das durações do movimento criadas nas casas quando apresentei a consolidação e a transformação de relações e pertencimentos suscitadas pelos trânsitos caseiros.

Os movimentos nas casas são alvos de considerações morais constantes, que afirmam as reputações de pessoas e famílias a partir de parâmetros como "ter a casa cheia", das pessoas que por ali passam e pelo tempo que permanecem. O valor dessas pausas criadas nas casas não se observa apenas desde a perspectiva de quem recebe, pois se pode dizer que andar é significativo à medida que se chega a uma casa. Entre os margeenses a própria circulação que move a localidade é descrita nos termos da "chegada": "chega lá em casa", "cheguei na casa de fulano", "vou dar uma chegadinha e já volto", "vamos chegando, povo!", "e vem o povo chegando!". Lembre-se que todos estes termos referidos à "chegada" também podem efetuar o convite a uma entrada mais formal: "vamos chegar?", o que não deixa de ser um chamado à recepção qualificada nos termos do "receber bem". ${ }^{11}$

Mas a casa também importa aqui por criar condições específicas para a efetuação e a variação dos movimentos. Os trânsitos experimentados nos termos das "chegadas", antes de suporem o fim de um movimento percorrido no espaço, traduzem outros movimentos, criados a partir deste lugar significativo para os deslocamentos. Não se entra e não se sai de qualquer jeito 
de uma casa: como chegar, como sair, por onde entrar, como permanecer, por quanto tempo, estas são questões prementes para aqueles que ali estão. A comparação entre os casos etnográficos da Terceira Margem, da localidade Buracos (Carneiro 2010) e da Zona da Mata e do Vale do Jequitinhonha (Comerford 2013) explicita um sem número de pressupostos e de condições relacionais que viabilizam que uma casa possa se configurar como um lugar em que se pode ser convidado ou instado a chegar, em que se pode chegar sem ser convidado e em que se pode efetivamente permanecer após chegar, por diferentes durações que são em si significativas para uma compreensão das relações (Comerford 2013). ${ }^{12}$

Por sua vez, chegadas, saídas e tantas outras formas de se fazer presente ou ausente incidem constantemente sobre as relações. Nesse sentido, apesar de o trânsito doméstico se fazer a partir de pressupostos mais ou menos esperados, nessas situações o esperado também se traduz em imponderável. As formas de chegar, de se fazer presente, circular pelos diferentes cômodos de uma casa, ausentar-se, além de indicarem quem mora e quem não mora ali, quem é visita e quem deixou de ser, são potentes em transformar proximidades e distâncias, a exemplo do dono da casa que passa a tratar seu vizinho como uma "visita" a fim de controlar suas investidas inconvenientes. Ou mesmo do conhecido, bastante chegado, que se aproxima de forma cerimoniosa de uma casa porque anteriormente observou movimentos pouco esperados: uma 'visita' que lhe constrange a chegada mais íntima e/ou um jeito mais arredio das mulheres na cozinha, e tantos outros modos explícitos ou não de desconsiderar as presenças.

Nessas situações, um traço característico da dinâmica hospitaleira replica-se nas diversas chegadas. Refiro-me ao que Herzfeld (2012) definiu como caráter experimental da hospitalidade, ao reconhecer que nada garante a felicidade ou a infelicidade dos atos de receber (um estrangeiro pode se sentir tanto em casa que ameaça a soberania e o espaço do dono, ou o dono da casa não realiza as condições do bem receber etc.), sendo estes elementos que afirmam a tensão constitutiva das relações hóspede-anfitrião. Do mesmo modo, no contexto das relações entre os mais chegados, a proximidade não é condição que garante o sucesso dos movimentos vividos na intimidade, pois há sempre um risco presente nas maneiras de circular e de permanecer numa casa. Não é à toa que assim como encontrei vários moradores que afirmaram seu gosto por 'ter a casa cheia', também conheci aqueles que preferiam manter as portas fechadas dos seus lares ou exercer outras formas de controle das presenças em sua residência. Essas atitudes, apesar de serem avaliadas negativamente pela comunidade, não deixam de ser compreensíveis, já que ninguém desconhece os problemas criados nessas idas e vindas domiciliares. 
Este último comentário sugere que, embora a prática hospitaleira seja transformada em tantas chegadas, algo das tensões constitutivas que marcam a relação anfitrião-hóspede (Pitt-Rivers 2012 [1977]; Herzfeld 1987, 2012), podem ser atualizadas e/ou recriadas nas movimentações dos mais próximos. Em trabalhos anteriores descrevi essa tensão constitutiva da existência a partir de práticas coletivas e práticas de si que marcam a convivência margeense. ${ }^{13}$ Desejo destacar agora como as ameaças e as tensões são problematizadas pelos margeenses em função das experiências mais diretamente voltadas aos deslocamentos e às circulações. A atenção a essas problematizações permite tratar um pouco mais sobre os diversos significados do "movimento" e de suas criações. É nesse sentido que esta discussão segue os rumos da "animação". ${ }^{14}$

\section{Animação}

Ao fazer circular pessoas, palavras, objetos, o movimento propicia que as experiências se tornem mais intensas. O barulho das conversas, das crianças, das pessoas que chegam ou se encontram na capela ou nas ruas da localidade, o burburinho criado pela música no salão de festas e pelos carros no dia dos festejos religiosos, os rojões, a cantoria, a bebida e a comida, os utensílios domésticos que vão e vem das casas em dia de festa, todos estes são elementos que fazem com que o momento seja "animado".

Quando o movimento é potente em criar a "animação", seu acontecimento não traduz apenas deslocamentos e circulações, ele remete aos estímulos e às intensidades que são produzidos a partir da concentração de tantos trânsitos (melhor dizendo, das "chegadas"). São estímulos e intensidades que trazem vivacidade às experiências e fazem com que um modo de vida seja mais promissor. 'Parece bicho do mato' é uma forma de dizer que um lugar sem movimento, no qual as pessoas não se esmeram em receber bem quem chega, em que não se vai às casas uns dos outros, em que não se festeja, é um lugar que desconsidera disposições mais cultivadas.

Da "animação" derivam outros adjetivos: a 'festa animada', o 'lugar animado'. Seu significado se estende, ressoa a fama de um povo: 'povo animado'. Mas mesmo nos lugares mais afamados pela agitação, não é sempre que o movimento se faz "animação". Espera-se que uma festa tenha movimento, porém, é muito comum ouvir os lamentos de que tudo estava muito parado. Seu acontecimento tem algo de imponderável e, do mesmo modo, é possível reconhecer algumas situações mais suscetíveis aos estímulos dos movimentos. Afinal, a animação pode ser criação momentânea advinda do 
encontro entre conhecidos e parentes numa casa ou por outros caminhos percorridos, mas há também aquelas movimentações mais incessantes que ganham força, permanecendo de forma mais duradoura, e o efeito dessa duração sobre a vida das pessoas pode definir um momento.

Dessas durações cria-se um "tempo". "Tempo da política", "tempo das festas", "tempo da colheita" são algumas das marcações importantes usadas pelos margeenses para tratar de contextos nos quais a vivência do movimento corresponde a uma transformação significativa. Essa tendência em caracterizar momentos da vida social a partir da noção de "tempo" não é exclusividade dos margeenses, que partilham as acepções 'tempo de antigamente', 'tempo da política' e 'tempo das festas' com outros coletivos. Sobre os povoados nordestinos onde realizou suas pesquisas, Moacir Palmeira (2002) argumenta que esses tempos indicam uma visão não orgânica da estrutura social: não se trata de uma vida dividida em âmbitos (política, religião, economia...), mas de uma vida na qual há associação entre tempo e ação adequada. A noção de tempo, enquanto recorte da vida social, estabelece marcações, concentra determinados acontecimentos e práticas: "Trata-se de criar um tempo próprio para o desempenho de determinadas atividades consideradas importantes pela sociedade" (Palmeira 2002).

A concentração de atividades que define um "tempo" indica esse recorte específico para as coisas, mas também pressupõe que, por estarem concentradas de determinada maneira, elas são vividas em ritmos diversos. É claro que há tempos mais ou menos animados do que outros, assim como pode variar a agitação conjuntural de cada tempo (há campanhas eleitorais - 'tempo da política' - mais 'quentes', por exemplo). No entanto, há atividades que são reconhecidas pelo movimento que elas criam e que são potentes em estimular acontecimentos e, assim, modificar o próprio ritmo da vida. A concentração de pessoas nas fazendas de café (quando é 'tempo da colheita') que faz com que as mulheres saiam com mais frequência para o trabalho fora de casa e permaneçam junto a homens e mulheres conhecidos ou não, a alteração do estado de ânimo das pessoas durante as festas e outros encontros (frequentemente motivada pelas conversas, bebidas e comidas) são exemplos desses momentos específicos, nos quais os trânsitos propagam outros impulsos.

Por sua vez, essa mudança de ritmo é possibilidade de criação. Entre os margeenses, a equação tempo/movimento/criação explicita-se principalmente quando se fala sobre a política. A expressão "na política há muito movimento, é quando as coisas acontecem", associa a campanha eleitoral municipal não apenas à mudança de cargos diretivos (prefeito, vereadores e todas as reordenações que essas mudanças causam numa cidade do 
interior), mas também aponta a alteração no cotidiano das pessoas e das próprias pessoas. Entre os margeenses, as campanhas são vividas através das manifestações 'partidárias', cujo efeito se observa tanto nos lugares quanto nas pessoas (as 'provocações' dão o tom das relações, frequentemente levando aos desentendimentos). É também uma atividade associada à "paixão", mais um elemento que faz com que seu movimento seja aceleração/ transformação da vida. ${ }^{15}$

A associação entre movimento e momentos mais agitados subentendem intensidades situacionais que são replicadas no comportamento das pessoas à medida que também são emocionais e corporais, tal como Dumans Guedes (2014) descreve para o caso das febres vividas pelos garimpeiros. Para os que vivem em Minaçu e estiveram no garimpo, o movimento não é apenas o do dinheiro e o das pessoas que vão em busca dele, mas igualmente o de experiências que mexem com os comportamentos (não é à toa que essa atividade recorta um tempo, um tempo de febre), de sorte que esse estado febril faz com que o homem busque o mundo, e possa se perder nele, voltando pra casa sem dinheiro ou vivendo uma vida de constantes mudanças, sem perspectivas de sossegar.

O exemplo de Minaçu nos remete às intensidades variadas supostas nos movimentos, as quais refletem tanto mudanças de ritmos quanto de natureza, pois assim como há momentos mais agitados do que outros, também há intensidades mais desejadas e outras menos desejadas. O efeito desse desvio do movimento é notável nas relações, pois se o ânimo torna a convivência apreciada, ele também pode conduzi-la aos rumos de uma aceleração que beira o "descontrole", reconhecem os margeenses.

O que é esperado quando o "movimento" se faz "animação" é o fato de que tudo termine 'controlado'. A condição ('controlado') para esse estado de coisas indica uma possibilidade de variação que não é desconhecida, pois é sabido que a concentração criada pela circulação de pessoas, alimento, bebidas e palavras pode se precipitar em 'falação', em 'desentendimento', em 'maldade'. Entre os margeenses teme-se um tempo em que as pessoas se 'descontrolavam' durante as festas, e a razão para tal descontrole era o consumo de bebidas. A lembrança do que decorria da inexistência da moderação faz com que muitos margeenses permaneçam abstêmios. A "animação" provinda da música, da prosa e da comida é suficiente para motivar uma participação menos refém dos riscos sempre presentes em situações movimentadas.

Ainda que esses e outros cuidados sejam observados, nem sempre é possível se precaver dos acontecimentos suscitados nesses contextos. Nas festas, a "ajuda" necessária pode vir do empréstimo de panelas e utensílios 
domésticos, os quais saem da casa de alguém para poder alcançar a casa de outro ou a cozinha da capela e, de lá, ganhar os salões. Terminada a festa, o esperado é que eles retornem limpos para a casa de onde vieram. Em certa situação, as panelas demoraram a retornar para a casa de sua dona. Sua insatisfação não deixou de ser expressa aos vizinhos mais próximos, do mesmo modo que sua reclamação precipitou as fofocas que tematizavam a intolerância da mulher. Enquanto uns concordavam com o fato de que o melhor era manter distância de circunstâncias como as festas (haja vista o desagrado que podem causar principalmente àqueles que ajudam), outros comentavam a má vontade de quem não sabia entender as condições do contexto, reclamando de tudo, até mesmo do sumiço de 'meia dúzia de garfos'.

Situações de desagravo como essas podem ocorrer no cotidiano. Todo morador que convive com as pessoas, seguindo o ritmo do ir e vir pelas casas, reconhece a inconveniência de uma "visita" que chega sem avisar ou a falta de atenção de quem a recebe. Não são poucas as reclamações das "ajudas" não retribuídas ou das pessoas que chegam às casas menos a fim de auxiliar e de se encontrar e mais interessadas em comentar sobre a vida alheia, dando ensejo à 'falação'.

As maneiras de reagir a essa variação do "movimento" são bastante diversas e o caso do sumiço das panelas ilustra algumas delas: há aqueles que sugerem abster-se das festas, não participando, mas esta parece ser uma atitude demasiadamente radical. O que é mais comum entre os margeenses é orientar-se através de precauções homeopáticas, que marcam um princípio ético e moral importante: "é preciso ter controle". Práticas como o "receber bem", a "visita" e a "ajuda" assinalam em seus próprios procedimentos essas precauções. O ritmo das chegadas constantes indica os momentos mais adequados para chegar (e para ir embora), que devem ser observados por aqueles que transitam pelas casas. Saber reconhecer o auxílio recebido através da oferta de um bem ou da própria presença é outra medida significativa na cadência do ir e vir mais familiar. No convívio com os moradores mais afeitos a falar dos outros, o aconselhável é mudar o rumo da conversa quando estes insistem na 'falação', e frequentar menos suas casas também é uma medida aconselhável.

É necessário saber viver as situações mais intensas, de modo que a "animação" demanda uma prática, pois seu acontecimento cria um estado de coisas específico que requer habilidade das pessoas. Assim como Allerton (2012) descreveu as visitas de Manggarai, ao tratar das condições necessárias para a criação de liveliness, na Terceira Margem se reconhece que há habilidades necessárias para se manter a condição do momento: 
os moradores que vão e permanecem nos festejos, a prosa que se estende, a comida que, sendo bem feita, agrada a todos, e a bebida servida a contento. Nas festas e nas casas, tais habilidades são justamente aquelas que caracterizam os atos de receber, ou seja, o cultivo da "animação" é feito principalmente por meio das investidas dos anfitriões e dos comportamentos das visitas e dos chegados.

Manter uma festa animada ou a "animação" também demanda um cuidado constante nessas situações tão propensas ao descontrole. Mas essa possibilidade é uma derivação da 'animação' que não diminui o interesse dos moradores em buscar movimentos que gerem intensidade. Pelo contrário, as circunstâncias que espreitam o descontrole parecem ser aquelas mais significativas em gerar a animação adequada. Mesmo sendo um tempo de 'desentendimentos', no qual a cidade que se quer pacata não encontra os modos de assim o ser, reconhece-se que a política é também "paixão", de sorte que, seja morador da cidade ou da roça, são poucos aqueles que conseguem disfarçar o gosto por seu acontecimento.

A busca por movimento e por animação indica que essa intensidade não deixa de ser necessária à convivência, pois ela faz precipitar algo que existe no mundo e nas pessoas, apesar de em alguns tempos existir de forma mais prevenida. As palavras barulham, há o excesso das comidas e das bebidas, a perambulação, o leva e traz das panelas e tantas coisas mais que possibilitam interagir e conhecer pessoas. Nesse sentido, as intensidades criadas pelos movimentos se apresentam como traços constitutivos das dinâmicas relacionais. Este é um argumento que partilho com Ana Carneiro (2014) em suas considerações para o caso dos Buracos ao tratar do sistema que faz um povo:

o comedimento também vai em outra direção: para que o povo seja "unido" é preciso que se produza entre eles "animação", Deus quer da gente é alegria, mas esta não pode "descontrolar". O equilíbrio instável e necessário balança portanto entre dois efeitos contrários de uma mesma ação, perigosa e desejada: "animar", dar movimento ao povo e às suas relações internas (Carneiro 2014:19; grifos originais).

As intensidades influem na modulação das estabilidades e das instabilidades que fazem parte da vida, pois sem movimento e sem animação um lugar não é comunidade, uma habitação não é uma casa no seu sentido pleno. Do mesmo modo é esperado que o ânimo mexa com cada um: uma pessoa muito 'controlada' deixa tudo mais sistemático, tal como dizem os buraqueiros (Carneiro 2014), tornando o convívio mais difícil e sem graça. 


\section{Considerações finais: nota sobre andar e conhecer}

Seguindo as disposições, sentidos e motivações que fazem do "movimento" uma experiência tão valorizada pelos margeenses, encontramos deslocamentos, práticas de circulação, acontecimentos que geram mudanças no ritmo da vida ("animação") e uma tendência a buscar ou a criar situações propícias ao seu acontecimento. Ao final dessa discussão, gostaria de acrescentar alguns comentários sobre essa busca, no que diz respeito a um conhecimento apreendido na experiência dos movimentos, pois entre aqueles que se movem é sabido que "andar é conhecer".

Andar é conhecer, expressão ouvida pelos pesquisadores do Cerrado Mineiro (Andriolli 2011; Carneiro 2010), sugere um modo de conhecimento que se faz em constantes circulações e que qualifica o próprio movimento. Para conhecer é preciso andar, mas de todas as andanças que as pessoas fazem são significativos os caminhos que as conduzem às situações nas quais é possível se tornar um dos próximos ou estar entre eles. Os movimentos podem expor pessoas a um mundo (Dumans Guedes 2014) estranho e muitas vezes hostil ao universo da casa, de sorte que movimentar-se pelo avesso desse universo envolve um trabalho de fazê-lo conhecido. Seja em busca de emprego (Novaes 2011), seja em viagens para visitar ou passar uma temporada na casa de familiares (Comerford 2013; Carneiro 2010), o trecho, o mundo (e tantas outras derivações que qualificam os destinos para São Paulo, Rio de Janeiro, lugares mais ou menos próximos de onde se partiu) são recriados nesses trânsitos a partir de operações de familiarização. Esses contextos etnográficos nos falam de pessoas que viajam com um parente ou que buscam um lugar distante e lá encontra um ambiente bastante familiar, construído pela presença dos próximos que chegaram anteriormente.

Não se descarta a opção de sair em busca do movimento mesmo que sozinho, mas esse sozinho tampouco traduz uma disposição individualista em conquistar outros lugares, conhecer novos mundos, tal como descreve Teixeira (2014) para o caso da moça de Catarina (município do sertão cearense) que se muda para trabalhar na casa de uma suposta desconhecida em Fortaleza. No primeiro encontro, elas descobrem que partilham relações, mas apesar de essa moradora conhecer e ser conhecida de pessoas próximas à moça de Catarina, a realização da proximidade não se concretiza entre as duas, o que faz com que a chegante se sinta desprezada em face da presença da outra: pai, eu tava tipo uma pessoa desprezada, minha sorte era uma vizinha que tinha lá e que me acolhia (Teixeira 2014:52). Em pouco tempo a moça volta para a casa dos pais. 
Andar é conhecer refere-se às andanças nas quais é possível conhecer, mas também tornar-se conhecido, à medida que não faz sentido circular por um mundo de estranhos sem a possibilidade de estabelecer proximidades que transformem relações. O conhecimento do mundo envolve um trabalho de se tornar conhecido que é ao mesmo tempo um exercício de se fazer reconhecido, tal como no caso da menina que vai trabalhar em Fortaleza, mas volta após se sentir desprezada. O exemplo indica a possibilidade de os movimentos estenderem e criarem um mundo similar ao dos parentes, mas também afirma que esta possibilidade nem sempre se concretiza com sucesso: a moça retorna ao lugar de origem, retorno este que, apesar de preconizar outras partidas, não deixa de significar a infelicidade desse trânsito particular.

Os movimentos que envolvem práticas efetivas de conhecimento pressupõem o estabelecimento de vínculos de proximidade ou o transitar por caminhos antes percorridos por parentes. Pode-se dizer para o caso da Terceira Margem, assim como para as outras realidades citadas, que as boas andanças (ou seja, aquelas nas quais é possível conhecer) estão referidas aos acontecimentos do parentesco, às possibilidades de estender e qualificar esses vínculos. Sem esquecer que são experiências vividas na iminência dos retornos não previstos, dos 'descontroles' e de outros riscos que preocupam, mas que ao mesmo tempo fazem com que tudo fique mais movimentado.

Recebido em 11 de janeiro de 2016

Aprovado em 17 de julho de 2016

Graziele Dainese é pós-doutoranda no Programa de Pós-Graduação em Antropologia Social, Museu Nacional, Universidade Federal do Rio de Janeiro, Rio de Janeiro/RJ, Brasil. E-mail: <grazidainese@hotmail.com> 


\section{Notas}

1 Este artigo reflete muitas discussões que foram feitas durante o curso Oficina de Pesquisa, ofertado por John Comerford no segundo semestre de 2014. Realizado no Programa de Pós-Graduação em Antropologia Social, Museu Nacional/UFRJ, o curso contou com a colaboração de Luzimar Pereira, Ana Carneiro, André Dumans Guedes, Luan Teixeira. Agradeço a todos eles pela oportunidade de discutir as ideias que aqui foram expostas, assim como não os responsabilizo por qualquer equívoco que elas possam expressar. Uma versão deste artigo foi apresentada na IV Reunião de Antropologia do Norte e Nordeste no ano de 2013. Nesse mesmo ano apresentei outra versão em uma reunião do Núcleo de Antropologia Simétrica (Nansi) do PPGAS/Museu Nacional. Aos membros desse núcleo e aos participantes do grupo de trabalho Mobilidades Urbanas e Rurais no Brasil Contemporâneo também agradeço a oportunidade.

2 Em Instituições políticas brasileiras, Oliveira Viana (1955 [1949]) opõe dois modos de formação social agrária: a comunidade de aldeia e as comunidades dispersas. A primeira é identificada com o continente europeu e a América do Norte e a segunda, às comunidades rurais brasileiras. Tal oposição se funda na suposição de que a falta de um espírito solidário e a existência de uma vida associativa em nosso meio rural se devem ao isolamento e à dispersão que marcam os territórios rurais nacionais, dispersão e isolamento estes que, aos olhos do autor, não se resumem ao aspecto físico, mas dizem respeito também ao aspecto existencial dos moradores desse território. O contrário é atribuído às comunidades de aldeia, cuja forma geográfica das casas, mais próximas umas das outras, seria uma atualização de práticas vicinais e associativas intensas e gregárias. Quando comparadas com essa forma de sociabilidade, as comunidades dispersas se caracterizam pela negação do solidarismo local e por uma vida privada que impede vínculos políticos mais sólidos.

3 O entendimento da migração como um fenômeno de esvaziamento dos campos e do povoamento das cidades tornou-se senso comum, equacionado em abordagens que concebem essa mobilidade como exôdo rural (ver Palmeira \& Wagner 1977). Preocupados em entender as especificidades do trânsito campo-cidade para além do eixo explicativo dado pelo tema êxodo rural, alguns pesquisadores argumentam que as transformações não seguem um deslocamento unilinear, posto que, ao migrarem, os moradores não abandonam a roça em definitivo. Estudos como o de Woortmann (1990) argumentam que muitas vezes a mobilidade é feita em razão de um retorno e, neste caso, trata-se de um modo de criar as condições para permanecer no campo. Quem migra deixa famílias e roçados em busca da possibilidade de um ir e vir.

4 Santa Abadia do Pradinho é o nome fictício que criei para o município no qual realizei a pesquisa de campo. O trabalho de pesquisa compreendeu distintos momentos do período de 2008 a 2009. Na ocasião, frequentei tanto o núcleo urbano quanto as localidades rurais. Cabe informar que o município é habitado por 30.000 pessoas, sendo que sua maioria se encontra nas 19 localidades rurais ali existentes. Vizinhas ao núcleo urbano (vizinhança esta que compreende uma distância de 5 até 
$70 \mathrm{~km}$, a exemplo da comunidade Tijucas, a mais longínqua), nessas localidades seus moradores se dedicam a atividades diversas, principalmente à produção de leite e derivados (queijo), grãos (feijão, milho) e frutas para subsistência. Em algumas delas também se encontra a produção de café, embora este cultivo (dada a proporção de investimentos financeiros necessários) seja atividade predominante entre os grandes produtores que, em sua maioria, residem no núcleo urbano e não nas localidades. Também é preciso dizer que neste artigo priorizo o tempo de convivência com os moradores de uma única localidade: a Terceira Margem, lugar habitado por 100 pessoas. A maior parte dos margeenses se ocupa com as atividades agrícolas ali desenvolvidas (produção de leite, grãos e café), seja como proprietários da terra, seja como trabalhadores ocasionais e/ou permanentes nas terras dos seus vizinhos. Para um conhecimento mais detalhado da configuração social e econômica desse município e da Terceira Margem, indico minha tese de doutorado (Dainese 2011), trabalho do qual derivam as considerações tecidas neste texto. A fim de preservar seus moradores optei por usar denominações geográficas e pessoais fictícias, à exceção das designações regionais e estaduais.

5 Roça é um termo polissêmico, pois pode tanto se referir à zona rural quanto a um espaço dedicado a cultivos específicos numa propriedade. Recorrentemente, planta-se o milho que será utilizado para a alimentação bovina, feijão e frutas. Esta designação atribuída a determinados cultivos também visa distingui-los da produção de café, cuja ocorrência não se encontra em qualquer propriedade (como já foi dito, apenas alguns moradores dedicam uma parte de seu trabalho a este cultivo, o qual é predominante em terras de grandes produtores. Ver Dainese 2011). Quando um produtor trabalha com todas essas culturas, é comum diferenciá-las entre a "roça" (que, neste caso, encontra referência também no diminutivo, "rocinha") e o café.

6 Um comentário sobre as marcações gráficas: aspas duplas (" ") são utilizadas para os termos que são problematizados etnograficamente ao longo do texto. Aspas simples (' ') para os termos e as expressões de uso comum entre as pessoas com as quais trabalhei. O itálico é usado para os trechos citados a partir das referências bibliográficas.

7 Para um conhecimento mais detalhado de dinâmicas festivas semelhantes àquelas vividas na Terceira Margem, ver Pereira (2011).

8 Boa parte das localidades rurais de Santa Abadia do Pradinho está vinculada às paróquias católicas do núcleo urbano. Algumas dessas localidades têm em seu próprio território uma capela nas quais se realiza uma série de rituais religiosos, inclusive as festas anuais dos padroeiros de cada localidade. Há um calendário de festas que rege esses festejos. Na Terceira Margem as datas principais são maio e outubro, momentos nos quais se festejam Santa Abadia e São Benedito. A existência da capela faz da localidade uma "comunidade" no registro paroquial e municipal e esse recorte institucional é importante para a participação em programas municipais, bem como na vivência da Igreja. Adiante descrevo como para os moradores da Terceira Margem ter uma capela e ser "comunidade" são condições relacionadas a ter "movimento". Tal correlação desloca os sentidos mais institucionais da "comunidade", afetando-o por experiências outras. Para um conhecimento mais detalhado da organização institucional dessas "comunidades", ver Dainese (2011). 
9 Outras realidades etnográficas assinalam a importância dos movimentos na constituição de lugares significativos da vida das pessoas, os quais, antes de suporem espaços geográficos ou a fixação territorial, indicam adensamentos criados a partir de dinâmicas específicas de circulação e deslocamento. Minha inspiração para pensar sobre vidas que se fazem na movência e em lugares que indicam paradas mais ou menos duradouras (em vez de estabilidade e permanência absoluta) se baseia, além dos trabalhos já citados, nas considerações de Ingold (2011), nas descrições sobre os Mbya-guarani (Pissolato 2007), sobre os Tsimanes da Bolívia (Ellis 1996), assim como na etnografia sobre Minaçu (Dumans Guedes 2013) e dos argonautas de Gawa (Munn 1992).

10 Em trabalho anterior (Carneiro \& Dainese 2015), ao partir da leitura de etnografias que tratam de movimentações diversas, destacamos que diferentes movimentos se definem a partir de suas próprias paradas. As etnografias demonstraram como essa relação é bastante variável pois, à medida que ela difere, ela também os difere. A experiência etnográfica na Terceira Margem repõe em seus próprios termos a correlação intrínseca entre movimentos e durações de modo a expor a variação específica de sua tendência movente, assim como traz elementos para problematizar aspectos da hospitalidade que estão referidos ao modo como as casas participam das movimentações.

\section{Agradeço esta observação feita por John Comerford.}

12 Para o contexto da Zona da Mata e de Jequitinhonha, Comerford (2013) também chama a atenção para a maneira como o movimento de fora das casas replica-se nos movimentos vividos dentro delas, e como essa conjugação de acontecimentos transforma tais lugares num emaranhado de movimentos.

13 Seja nos momentos de "desentendimento" e na "política", seja nas considerações sobre o que faz uma pessoa e o seu modo de viver, tais problematizações sugerem que as ameaças, os perigos e as tensões da convivência, antes de serem acontecimentos advindos do contato com pessoas estranhas ou de serem criações de situações extraordinárias, afirmam uma condição existencial marcada por rumos malfazejos e por uma tendência agonística particular às relações mais íntimas. Sobre esse assunto, ver Dainese (2011, 2015b).

14 Pensar a relação hóspede-anfitrião como uma dinâmica relacional específica, mas que pode ser profícua para tratar de outros vínculos, é uma questão abordada por diferentes autores. Sobre essas diferentes abordagens, destaco: Pitt-Rivers (2012 [1977]) e sua problematização da hospitalidade a partir da relação com o estrangeiro; Herzfeld (1987) e o foco sobre a dimensão hostil da relação hóspede-anfitrião (assim como a conexão entre cortesia e agonismo que marca os atos de receber $(1987,2012)$. Também indico o trabalho de Shryock (2012), que versa sobre o tema da soberania desde os pressupostos da hospitalidade jordaniana. No presente artigo, minha abordagem da hospitalidade se faz pelo recorte do "movimento", a fim de entendê-la como uma das práticas significativas em criar esse acontecimento tão valorizado. No entanto, percebo também sua importância ao sugerir um modelo relacional que pode ser problematizado tanto para a relação com os desconhecidos quanto para a convivência entre próximos. 
15 O "partidarismo" traduz não apenas a orientação para votos, mas principalmente um princípio divisor atualizado pela política - uma dinâmica que é, sobretudo, a de se localizar em um dos dois 'lados', que podem ser nomeados por siglas mais atuais, as quais podem ser tranquilamente substituídas por inscrições já desaparecidas, tal como UDN - União Democrática Nacional, e PSD - Partido Social Democrático, denominações existentes nos anos de 1945 a 1964. A lógica partidária local impõe posicionamentos que, por sua vez, não implicam apenas votos, mas demandam outras formas de participação. Estourar rojões, ouvir jingles, portar bandeiras do candidato - estas e outras são maneiras de expor publicamente seu posicionamento, manifestações necessárias a um momento em que a neutralidade tem pouco crédito.

\section{Referências bibliográficas}

ALLERTON, Catherine. 2012. "Making guests, making 'liveliness': the transformative substances and sounds of Manggarai hospitality". Journal of the Royal Anthropological Institute, (N.S.): S49-S62.

ANDRADE, Carlos Drummond de. 2002 [1930]. Alguma poesia. Rio de Janeiro: Record.

ANDRIOLlI, Carmen. 2011. Sob as vestes de Sertão Veredas, o Gerais. "Mexer com criação" no Sertão do IBAMA. Tese de doutorado, Programa de Pós-Graduação em Ciências Sociais, Universidade Estadual de Campinas.

CANDIDO, Antonio. 1977. Os parceiros do Rio Bonito: estudo do caipira paulista e a transformação dos seus meios de vida. São Paulo: Duas Cidades.

CARNEIRO, Ana. 2010. O "povo" parente dos Buracos: mexida de prosa e cozinha no cerrado mineiro. Tese de Doutorado, Programa de PósGraduação em Antropologia Social/ Museu Nacional/ Universidade Federal do Rio de Janeiro.

. 2014. Mulher é trem ruim: corpo, comida e sistema. Ms.

. \& DAINESE, Graziele. 2015. “Notas sobre diferenças e diferenciações etnográficas do movimento". Ruris, 9(1):143-166.
COMERFORD, John. 2013. Vigiar e narrar. Sobre formas de observação, narração e julgamento de movimentações e associações. Ms. .; CARNEIRO, Ana; DAINESE, Graziele (orgs.). 2015. Giros etnográficos em Minas Gerais: casa, conflito, Comida, prosa, política, festa e o diabo. Rio de Janeiro: Editora Sete Letras.

DAINESE, Graziele. 2011. Chegar ao cerrado mineiro: hospitalidade, política e paixões. Tese de Doutorado, Programa de Pós-Graduação em Antropologia Social/ Museu Nacional/ Universidade Federal do Rio de Janeiro.

. 2015a. "Desentendimentos entre parentes: variações da intimidade". Revista de Antropologia, 58(2):371389.

. 2015b. "Chegar à Terceira Margem: um caso de prosa, paixões e maldade". In: John Comerford; Ana Carneiro \& Graziele Dainese (orgs.), Giros etnográficos em Minas Gerais. Rio de Janeiro: Editora 7 Letras. pp. 45-66.

DUMANS GUEDES, André. 2013. O trecho, as mães e os papéis: etnografia de movimentos e durações no Norte de Goiás. São Paulo: Garamond. 
. "Fevers, movements, passions and dead cities in Nothern Goias". Vibrant - Virtual Brazilian Anthropology, 11(1):56-95.

ELLIS, Rebecca. 1996. A taste for movement: an exploration of the social ethics of the tsimanes of lowland Bolivia. PhD, University of St. Andrews.

HERZFELD, Michael. 1987. "'As in your own house': hospitality, ethnography, and the stereotype of mediterranean society". In: D. D. Gilmore (ed.), Honor and shame and the unity of the Mediterranean (Special Publication $\mathrm{n}^{\mathrm{O}}$ 22). Washington, D.C.: American Anthropological Association. pp. 75-89.

. 2012. "Afterword: reciprocating the hospitality of these pages". Journal of the Royal Anthropological Institute, 18: S210-S217. doi: 10.1111/j.14679655.2012.01773.x

INGOLD, Tim. 2011. Being alive. Essays on movement, knowledge and description. London: Routledge.

MUNN, Nancy. 1992. The fame of Gawa. A symbolic study of value transformation in Massim society. Durham: Duke University Press Books.

NOVAES, Roberta. 2011. Gente de fora. Vida e trabalho dos assalariados do café em uma região de Minas Gerais. Rio de Janeiro: E-papers.

OLIVEIRA VIANA, Francisco José de. 1955 [1949]. Instituições políticas brasileiras. Vol. 2. Rio de Janeiro: Livraria José Olympio Editora.

PALMEIRA, Moacir \& ALMEIDA, Alfredo W. B. 1977. A invenção da migração. Projeto emprego e mudança socioeconômica no Nordeste (Relatório de Pesquisa). Rio de Janeiro: Museu Nacional-UFRJ. Mimeo.

PALMEIRA, Moacir. 2002. "Política e tempo: nota exploratória". In: Mariza Peirano (org.), O dito e o feito: ensaios de antropologia dos rituais. Rio de Janeiro: Relume-Dumará. pp. 171-178.
PEREIRA, Luzimar. 2011. Os giros do sagrado: um estudo etnográfico sobre as folias em Urucuia - Minas Gerais. Rio de Janeiro: Editora 7 Letras.

PISSOLATO, Elizabeth. 2007. A duração da pessoa. Mobilidade, parentesco e xamanismo mbya (Guarani). São Paulo: Editora da Unesp.

PITT-RIVERS, Julian. 2012 [1977]. "The law of hospitality". In: The fate of Shechem, or the politics of sex: essays in the anthropology of the Mediterranean. Cambridge: Cambridge University Press (Republicado em Hau: Journal of Ethnographic Theory, 2 (1):501-517).

SHRYOCK, Andrew. 2012. "Breaking hospitality apart: bad hosts, bad guests, and the problem of sovereignty". Journal of the Royal Anthropological Institute, (N.S.):S20-S33.

SÁ, Maria Auxiliadora Ferraz de. 1974. Dos velhos aos novos coronéis: um estudo das redefinições do coronelismo. Recife: Pimes.

TEIXEIRA, Jorge Luan. 2014. Na terra dos outros: mobilidade, trabalho e parentesco entre os moradores do Sertão do Inhamuns (CE). Dissertação de Mestrado, Programa de PósGraduação em Antropologia Social/ Museu Nacional/ Universidade Federal do Rio de Janeiro.

THOMAS, William I.; ZNANIECKI, Florian. 1974 [1918]. The Polish peasant in Europe and America. 2 vols. New York: Octagon Press.

WOORTMANN, Klaas. 1990. “MigraÇão, família e campesinato". Revista Brasileira de Estudos da População, 7(1):35-43. 


\section{MOVIM ENTO E ANIMAÇÃO DAS FESTAS, VISITAS, ANDANÇAS E CHEGADAS}

\section{Resumo}

Neste artigo apresento a proliferação e a especificidade das motivações, dos sentidos e dos circuitos que se encontram subsumidos no "movimento" vivido na Terceira Margem (localidade rural situada no cerrado mineiro). A descrição dos diversos modos de movimentar e de fazer movimento se baseia nas práticas de circulação (como "receber bem", "visitas", "ajudas"), nos acontecimentos que levam às andanças e, principalmente, às "chegadas" às casas de parentes e conhecidos. A partir desses acontecimentos serão discutidas as influências dos deslocamentos, das circulações e de outras criações do "movimento" sobre as relações vividas pelos margeenses nos encontros com os estranhos e na convivência com os mais próximos.

Palavras-chave: Movimento, Circulação, Hospitalidade, Animação.

\section{MOVIMIENTO Y ANIMACIÓN DE LAS FIESTAS, VISITAS, ANDANZAS Y LLEGADAS}

\section{Resumen}

En este artículo presento la proliferación y la especificidad de las motivaciones, los sentidos y los circuitos que se encuentran incluidos en el "movimiento" vivido en la Tercera Margen (localidad rural situada en las montañas del estado de Minas). La descripción de los diversos modos de moverse y de hacer movimiento está basado en las prácticas de circulación (como "recibir bien", "visitas", "ayudas"), en los acontecimientos que llevan a las andanzas $y$, principalmente, las "llegadas" a las casas de parientes y conocidos. A partir de estos acontecimientos serán discutidas las influencias de los desplazamientos, las circulaciones y otras creaciones de "movimiento" sobre las relaciones vividas por los margeenses en los encuentros con los extraños y en la convivencia con los más cercanos.

Palabras clave: Movimiento, Circulación, Hospitalidad, Animación. 
M OVEMENT AND LIVELINESS IN FEASTS, VISITS, WANDERINGS AND ARRIVALS

\begin{abstract}
In this article I deal with the proliferation and the specificity of motivations, meanings and circuits subsumed in the experience of movement which takes places in Terceira Margem, a rural community located in the cerrado region in the state of Minas Gerais.
\end{abstract}

The description of the different modes of movement is based on the practices of circulation, such as hospitality, visiting, and helping, and on the causes of the wanderings and the arrivals at the houses of kinspeople and acquaintances. Finally, I discuss the implications of the different expressions of movements on the Margeens in their meetings with strangers and relatives.

Key words: Movement, Circulation, Hospitality, Liveliness. 